\section{Col 15}

THE SIGNIFYING VALUE OF CA 19-9 COMPARED TO CEA IN GASTRIC AND COLORECTAL CARCINOMA F. Safi, R. Bittner, R. Roscher, H.G. Beger

It is well-known fact that fumor markers are used to investigate whether malignant tumors have been operated sufficiently and radically and to rectify or falsify a renewed growth of the tumor. After CA $19-9$ had proved to be a highly sensitive marker in the differential diagnosis between pancreatic carcinoma and chronic pancreatitis as well as in the perioperative follow-up, it was the aim of the present study to compare the monoganglioside antigen CA19-9 with CEA with regard to its sensitivity (SE) and specificity (SP) in diagnosing the different stages of colorectal and gastric carcinoma and in detecting recidivation during the aftercare treatment. Pre- and postoperatively CA 19-9 and CEA are estimated in 82 pts. with colorectal carcinoma (CRC) and in 57 pts. with gastric carcinoma (GC) radioimunologically.

\begin{tabular}{lrrrrrrrr} 
Results: & \multicolumn{4}{c}{ Tumor stages (GC) } & \multicolumn{4}{c}{ Tumor stages (CRC) } \\
\hline CA 19-9 & I & II & III & IV & I & II & III & IV \\
$6-37 \mathrm{U} / \mathrm{ml}$ & 15 & 10 & 4 & 7 & 22 & 23 & 7 & 15 \\
$>37 \mathrm{U} / \mathrm{ml}$ & 1 & 4 & 5 & 11 & 1 & 1 & 2 & 11 \\
CEA & & & & & & & & \\
$<3 \mathrm{ng} / \mathrm{ml}$ & 11 & 8 & 3 & 5 & 16 & 14 & 3 & 8 \\
$>3 \mathrm{ng} / \mathrm{ml}$ & 5 & 6 & 6 & 13 & 7 & 10 & 6 & 18
\end{tabular}

The comparison depending on stages between the markers CFA and $C A$ 19-9 shows an increased sensitivity of the CEA in all stages of GC and CRC. In our cases of 66 pts. with GC and 165 pts.with CRC who were all surgically treated, CA 19-9 and CEA were estimated at the same time in the outpatients' department. From the exact clinical evaluration of CA 19-9 and CEA estimation in these patients the following conclusion could be established: CEA is more sensitive than CA 19-9, but CA 19-9 is more specific. The sepcificity, sensitivity, and total accuracy increases, if both markers are used.

Dep.of General Surgery, Univ.of Ulm,Steinhövelstr.,D-790uM

Col 16

FADING CLINICAL RELIABILITY OF SERIAL LONG-TERM CEA-DETERMINATIONS DUE TO MULTIPLE RIA-KITS

J. Spitz

In the last years the consequent monitoring of serum CEA values has become a solid pillar in the follow-up controi of GI cancer patients. Consequently an increasing number of CEA-RIA kits appeared on the European market. Previous own observations as well as sporadic hints in the Titerature indicate, that there is a lack of comparibility between the results of different kits.

Material and Methods: We therefore checked 12 different products (Abbott monoclonal and polyclonal, Amersham, Behring, Bio Sorin, Byk Mallinckrodt, Hybritech, ID CIS polyclonal and monoclonal, Medtro and Serono), simulating a follow-up study of cancer patients, using the same serum probes for CEA determination with the different kits (380 prabes für 3594 estimations).

Results: While the overail correlation of the kits was quite good, $(r=0,73-0,89)$, the slopes of the correlation curves varied remarkably $(0,7-2,1)$. The comparison of individual results however was alarming: A pooled serum for quality control differed over $100 \%$ $(19,0-42,5)$. A 1:1 dilution of the WHO-standard 2/22 J corresponding to $20 \mathrm{ng} \mathrm{CEA} / \mathrm{ml}$ showed variations over $500 \%$ $(5,9-30,2)$. Depending on the "accidental" sequence of the used kits, patients showed remission (46-39-31-25-24-23-21-21-20-19-18-7) or bad progress $(4-5-6-7-7-9-10-11-11-17-19-23)$ or intermitting course of tumor disease $(17-14-10-11-15-18-12-11-3-11-16-20)$.

Conclusion: Serum-CEA-values of one patient estimated by different products must not be compared with each other and are worthless for long-term follow-up control! CEA values therefore can only be accepted, if the name of the kit producing company ist declared. Differs the company from the one in the own lab, the value has to be controlled to assure a correct long-term follow-up and to avoid annoying pitfalls.

Städt. K1in. Wiesbaden, L.-Erhardstr.100, D 62 Wiesbaden

\section{Col 17}

C3-ACTIVATIOH CAPACIIY IN THE SERUH OF COLORECTAL CANCER-PATIENTS-TUHOR DRAINIMG-BLLOOD VERSUS PERIPHERAL BLOOD

H. Betzler, H.K.Schackert, H. Ernst, D. Flad 2, L. Edler ${ }^{3}$

Opsonization of bacteria or fragments of the bacterial cell wall increases the binding to and phagocytosis by monocytes. Specific IgG binding or $C 3 b$ activation and binding are two different pathways. Monocytes are stimulated as even via $F c$ receptors as via c $3 b$ receptors. The stimulation of monocytes is followed by a respiratory burst which is characterized by a non mitochondrial oxygen consumption. There is a consecutive production of activated oxygen species, which generate chemiluminescence after relaxation and photon emission. The aim of this study was to evaluate the $C 3$ activation capacity (AC) in controls and colorectal cancer patients of different stages by monocyte mediated chemiluminescence. Methods: 48 patients ( 14 controls and 34 colorectal cancer) were examined for the $\mathrm{C} 3$ activating capacity. Blood was drawn from the cubital vein and separated serum was frozen at $-70^{\circ} \mathrm{C}$. To evaluate the $\mathrm{C} 3 \mathrm{AC}$ each serum sample was divided in two portions, one remaining untreated (activel and the other being inactivated (inactive) at 56 oc for $30 \mathrm{nin}$. $4 \times 10^{5}$ isolated nononuclear cells including monocytes and lymphocytes of healthy donors were incubated in $300 \mu \mathrm{L}$ DMEM and $10 \mu \mathrm{l}(2 \mathrm{mg} / \mathrm{ml})$ luminol. $36 \mu \mathrm{l}$ of either active or inactive serum was added and $\mathrm{CL}$-reaction was started by adding 10 fil zymosan $(5 \mathrm{mg} / \mathrm{ml})$. 20 minute integral relation of the dynamic CL-measurement of activated and inactivated serull was named $C 3 b-i n d e x$ and expressed as percentage of a standard serum $A C$. Results: Controls had the highest C3 AC (14/92.5/85.2-99.8/95\% confidence interval). Colorectal cancer patients with the stage $T M_{0} M_{0}$ had significantly lower values $(18 / 72.2 / 57.0-87.4 / p=0.009)$ in contrast to I N M patients (12/81.6/69.7-93.8/n.s.). The mean AC in T N M cancer patients was found to be $54.7 \quad(n=4)$; significance was set at ${ }^{+}+0.05$ using the Wilcoxon signed rank test.

Conclusion: These results indicate that the demonstrated phenonena of a decreased $C A$ in colorectal cancer patients which was more pronounced in the tumor draining than in the peripheral blood could be related to a complenent consumption in tumor patients, especially in the tumor region. This effects may be due to an increased complement activation by tunor antigens.

Chir. Univ. Klinik Heidelberg, Abtl. 2.1.1, 6900 Heidelberg (1)

Forschungsinstitut Borstel, 2061 Borstel (2)

DKFZ Heidelberg, Abtl. Biostatistik, 6900 Heidelberg (3)

\section{Col 18}

PLASHA MELATONIN IN PATIENTS UITH GASTROINTESTIMAL CARCINOMA

\section{Stemine, R. Khoory, Skalicky and V.Schloot}

Tha pineal gland is a neuroendocrine trangducer which is involved in the process of biological shythas of the organism. The link between the pineal gland or its specific hormone nelatonin and malignancy is dicussed since morphological change in this gland in autopsied cases bearing neoplasias were aade (N, Lapinin Pinaal Gland and Malignancy, 2, Onkol, 3, 51-60, 1976, In aniba! models melatonin is knovn to decrease the growth of tumours and their metastasis $\{L, R$. Stanberry et al, Photoperiodic Control of Melanona Growth in Hansters: Influence of Pinealectomy and Melantonin, Endocrinology $113,469-473$, 1983), A reduced melantonin production during nighttime $(\mathrm{L}$, Tarmarkin et al, Decreased Nocturnal Plasma Melatonin Peak in Patients with Estrogen Receptor Positive Breast Cancer. Science 216, 1003-1005, 1982) or the absence of physiological day-night-rhythm in plasua aelatonin levels in patients with cancer (Ert breast cancer, prostata cancer) were found (C. Bartsch at al.: Circadian Rhythrs of Serun Melatonin, Prolactin and Grouth Hornone in Patients with bengin and malignat Jumors of the Prostata and in non-tumor Controls, Neuroendocrinol, Lett, 5, 377-386, 1983), Whe thus examined melatonin levels in patients suffering fram gastrointestinal carcinona, Blood samples were collected between 11,30 and 12,30 houp (daytima) and between 23,30 and 0,30 hours (nighttine) from 34 patients hospitalized for non-malignant diseases and from 12 patients with diagnosis of gastrointestinal carcinoua, A jodinated aelatonin RIA has been used for the determination of plasma melatonin concentrations.

In controls we observed grast interindividual variability in melatonin levels during daytirire, Mean value for this sample was $40 \mathrm{pg} / \mathrm{ml} \pm 7 \mathrm{gEM}$. Mean daytime value for patients with gastrointestinal carcinona was $26 \mathrm{pg} / \mathrm{ml} \pm 6$ SEM, Nighttime values were even more variable in both groups, Mean value for controls during nighttiue was 94 po/hil \pm 24 SEM, Nightidat value of gastrointestinal. cartinowa was $42 \mathrm{pg} / \mathrm{ml} \pm 6$ SEM, There was no statistical significance between daytine or nighitime melatonin levels in patients with gastrointestinal carcinona and controls. The ratio night/day nelatonin level in controls was 2,9; in patients with gastrointestinal carcinona 1,6 , This differente was statistically significant on $p<0,05$ (student- $t$-test). Thus, the abaence of nocturnal peak nelatonin (indicated by decreased ratio of night/day-melatonin plasma level) may serve as a biochentcal marker for insreased risk of developing gastrointestinal canter as discussed by others for breast cancer (see L, Taraarkin), But because of the high interindividual variability in plasal melatonin levels in patients vith gastrointestinal carcinoma and in controls further investigations about this phênokennen are necasary. Chirurg.Klinik, ZKH L.inks der Weser,2800 Bremen 